\title{
Tones (Sounds) Loudness Surface: the Weber' Law for Hearing
}

\author{
Ovchinnikov Evgeny L \\ Department of Medical and Biological Physics, \\ Samara State Medical University, \\ Samara, Russia
}

\begin{abstract}
Purpose: Research and theoretical substantiation of the hearing Weber law for sounds arbitrary frequencies and intensities.

Objects: Results of classic psychophysical experiments of Weber, hearing Fechner model (equation) as a special case of the Weber law.

Methods: Audiometric for determining hearing acuity, biophysical for the substantiation of auditory process, methods of mathematical analysis and computer simulation.

Results: To the analytical and graphical form is substantiated and submitted the hearing Weber law for arbitrary frequencies and intensities of sounds.
\end{abstract}

Keywords-sound (tones) loudness; loudness surface; weber' law for hearing; sounds of arbitrary frequencies and intensities.

\section{INTRODUCTION}

Person's perception of sound energy (intensity I or pressure P) in hearing physiology and psychophysics is estimated as loudness E sense and is installed by Weber Fechner law $[1,2]$. The law regulates the parity "the relative sound intensity I (sound pressure $\Delta \mathrm{p}$ ) with respect to the threshold intensity $\mathrm{I}_{\mathrm{o}}=\mathrm{I}_{\mathrm{oc}}=10^{-12} \mathrm{~J} /\left(\mathrm{m}^{2} \mathrm{~s}\right)$ (threshold sound pressure $\left.\Delta \mathrm{p}_{\mathrm{oc}}=2 \cdot 10^{-5} \mathrm{~Pa}\right)$, as relative strength of the stimulus, and its subjective sense - tones loudness E. "This means that the tones loudness is a psychoacoustic correlate of hearing perception of the sound energy (sound intensity, sound pressure).

Mathematical Fechner substantiation of the law for hearing on Weber experiments does not give a full and final decision and, of course, does not establish a functional link between the force and sense of irritation in the hearing perception of the sound energy of arbitrary parameters.

\section{STUDY RESULTS}

\section{A. Problems in hearing psychophysics}

Weber - Fechner law defined in integral form only for the standard frequency $\mathrm{f}_{\mathrm{c}}=1 \mathrm{kHz}$ as a declarative (conditionally accepted) relations

$$
\mathrm{E}, \text { phon }=10 \log \frac{\mathrm{I}}{\mathrm{I}_{\mathrm{o}}}, \mathrm{dB}=20 \log \frac{\Delta \mathrm{p}}{\Delta \mathrm{p}_{\mathrm{o}}}, \mathrm{dB} .
$$

In the general solution of the differential equation $\mathrm{dE}=$ $\mathrm{k}(\mathrm{dI} / \mathrm{I})$ as the Weber - Fechner in integral form $\mathrm{E}=10$ $\log \left(\mathrm{I} / \mathrm{I}_{\mathrm{o}}\right)$, the unit values on the right side is the decibel $(\mathrm{dB})$.
In practice, the tone's loudness as a response to stimulation (sensation) is evaluated the decibel loudness, equating to declaratively on the standard frequency decibel intensity and decibel loudness, calling his phon.For arbitrary frequencies and intensities of sound the Weber - Fechner law determined only experimentally and graphically is displayed as the curves of equal loudness - isophon. But it can be shown that the differential equation represented by Fechner as $\mathrm{dE}=\mathrm{k}(\mathrm{dI} / \mathrm{I})$, has a logical and a definite decision in the entire range of sound frequencies permissible (comfortable) intensity.

Experiments show that the auditory perception of a sound, greater or smaller standard frequency, but the same loudness as the standard sound requires an increase in the intensity of the sound on the new frequency at this level. First let us identify the causes of this phenomenon - a nature of tones (sounds) of equal loudness.

\section{B. Nature of tones (sounds) equal loudness}

Initially, let us clarify the physical, biophysical, physiological and psychophysical meaning of the quantity $\frac{I_{n f}}{I_{n c}}$ and substantiate the possibility of its calculation. This is the ratio of sounds intensities of equal loudness on nlevel loudness: two sound of an arbitrary $f$ and standard $f_{c}$ frequency of the n-level loudness are of equal loudness (produce the same sense of loudness) when performed the equation $E^{*}{ }_{n f}=E_{n c}^{*}$ in the receptor section of an inner ear. The equality of loudness tones interprets an answer of equal number $\mathrm{n}$ of sensors that are excited by stimulation, manifesting itself in subjectivity of sensations. But, according to Weber, this equality is an objective for the quantitative ratios of energy conversion in the receptor section.

Sounds with intensities $\mathrm{I}_{\mathrm{nf}}^{*}$ and $\mathrm{I}_{\mathrm{nc}}{ }_{\mathrm{nc}}$ (respectively, with energies $\mathrm{W}^{*}{ }_{n f}$ and $\mathrm{W}^{*}{ }_{\mathrm{nc}}$ ) will have equal loudness if they will have the same irritating effect on receptors: $\mathrm{I}_{\mathrm{nf}}^{*}=\mathrm{I}_{\mathrm{nc}}^{*}$, or, equivalently $\frac{\mathrm{I}_{\mathrm{nf}}^{*}}{\mathrm{I}_{\mathrm{nc}}^{*}}=1$. Introducing morphologic and functional parameters of the cochlear duct and using the definition of the wave intensity, expressing its connection with energy $\mathrm{W}$, we obtain 


$$
\frac{\mathrm{I}_{\mathrm{nf}}^{*}}{\mathrm{I}_{\mathrm{nc}}^{*}}=\frac{\mathrm{W}_{\mathrm{nf}}^{*}}{\mathrm{~W}_{\mathrm{nc}}^{*}} \frac{\mathrm{S}_{\mathrm{c}}^{*}}{\mathrm{~S}_{\mathrm{f}}^{*}} \frac{\mathrm{t}_{\mathrm{c}}^{*}}{\mathrm{t}_{\mathrm{f}}^{*}} .
$$

Here $\mathrm{S}_{\mathrm{c}}{ }_{\mathrm{c}}$ and $\mathrm{S}_{\mathrm{f}}^{*}$ - areas of basilar membrane which are occupies receptors, excited by waves of an arbitrary $f$ and standard $f_{c}$ frequencies, that are proportional to the square of the distance between the receptors $\Lambda_{\mathrm{s}}$ and $\Lambda_{\mathrm{f}}$. Coordinates of the receptors distribution $\ell(N)[3,4]$ along the basilar membrane of a length $\mathrm{L}_{\mathrm{o}}$, sensing a frequency $\mathrm{f}(\mathrm{N})$ at the maximum frequency of the perceived ear $\mathrm{f}_{\mathrm{mo}}=$ $20 \mathrm{kHz}$, are satisfied to acoustic-wave hearing model [5] $\ell(\mathrm{f})$ $=\mathrm{L}_{\mathrm{o}} \cdot 2^{2 \lg \frac{\mathrm{f}}{\mathrm{f}_{\mathrm{mo}}}}$ numbers $\mathrm{N}$ of excited receptors on ratio $\mathrm{f}(\mathrm{N})=\mathrm{f}_{\mathrm{mo}}$ ${ }_{10} \sqrt{\frac{1}{\lg 2} \lg \frac{\mathrm{N}_{\text {mo }}}{\mathrm{N}+\mathrm{N}\left(\mathrm{f}_{\mathrm{a}}\right)}}$, gives $\ell(\mathrm{N})=\mathrm{L}_{\mathrm{o}} \cdot 2^{\frac{-2}{\sqrt{\lg 2}} \sqrt{\lg \frac{\mathrm{N}_{\mathrm{mo}}}{\mathrm{N}+\mathrm{N}\left(\mathrm{f}_{\mathrm{a}}\right)}}}$ Then the distances between adjacent receptors $\Lambda(f)$ may be calculated from the obvious equation $\Lambda(\mathrm{N})=\ell(\mathrm{N}+1)-\ell(\mathrm{N})$ (Figure 1a).

In the same ratio $\mathrm{t}_{\mathrm{c}}{ }_{\mathrm{C}}$ and $\mathrm{t}_{\mathrm{f}}{ }_{\mathrm{f}}$ is duration of passing waves of compared frequencies clearance $h$ between vestibular and tectorial membrane (transfer of energy). This value (in the axial duct profile) is not experimentally determined. We can assume that clearance is constant over the entire length of the cochlear duct (with the possible exception of small areas at ends it). The result is greatly simplified by assuming that the lumen is inversely proportional to the distances between the receptors. Then $\frac{\mathrm{t}_{\mathrm{c}}^{*}}{\mathrm{t}_{\mathrm{f}}^{*}}=\frac{\mathrm{h}_{\mathrm{c}} / \mathrm{v}_{\mathrm{c}}}{\mathrm{h}_{\mathrm{f}} / \mathrm{v}_{\mathrm{f}}}=\frac{\Lambda_{\mathrm{f}}}{\Lambda_{\mathrm{c}}} \frac{\mathrm{v}_{\mathrm{f}}}{\mathrm{v}_{\mathrm{c}}}$, where $\mathrm{v}_{\mathrm{f}}$ and $v_{c}-$ velocity waves of arbitrary $f$ and standard $f_{c}$ frequencies, obeying dispersion in inner ear liquids according acoustic-wave hearing model [5] and satisfying the relation $\mathrm{v}(\mathrm{f})=\frac{1+2^{2 \log \left(\mathrm{f} / \mathrm{f}_{\mathrm{mo}}\right)}}{2} \cdot \mathrm{v}_{\mathrm{mo}}$, where $\mathrm{v}_{\mathrm{mo}}=$ $1600 \mathrm{~m} / \mathrm{s}$ - the sound velocity in the perilymph with the highest perceived by ear frequency $f_{m o}$ (Figure 1b). Finally, we obtain

$$
\frac{\mathrm{W}_{\mathrm{nf}}^{*}}{\mathrm{~W}_{\mathrm{nc}}^{*}}=\frac{\Lambda_{\mathrm{f}}}{\Lambda_{\mathrm{c}}} \frac{\mathrm{v}_{\mathrm{c}}}{\mathrm{v}_{\mathrm{f}}}=\mathrm{G}(\mathrm{f}) .
$$

Thus ratio of the energy of sound waves of arbitrary and standard frequencies for tones equal loudness in the inner ear directly proportional to the ratio of the distance between the receptors and inversely proportional to the relative velocities of the partial waves in fluids of the inner ear. Dimensionless quantity $G$ (f) defines the ratio of the energies of tones equal loudness: it shows how many times one of them must be larger than the other for sensations of tones of equal loudness, and can serve as a criterion of tones equal loudness, but varying pitch. Its special feature is to determine through parameters of inner ear (the distances between the auditory receptors and the endolymphatic duct clearance) and the physical characteristics of sound (velocity of dispersed waves in liquids of the cochlea).

\section{Nature of tones (sounds) equal loudness}

Note that the sound intensity (pressure) set by its definition in the environment. Entering on eardrum of the relative energy of waves of arbitrary frequency $\mathrm{W}_{\mathrm{nf}}$, divided by the energy of waves standard frequency $\mathrm{W}_{\mathrm{ns}}$, is equal to the relative intensity of these waves $\frac{W_{n f}}{W_{n c}}=\frac{I_{n f}}{I_{n c}}$, since the energy falls on one and the same surface - on the eardrum $\left(\mathrm{S}_{\mathrm{ed}}=\right.$ const $)$ and the duration of the passage of the wave distance from the inlet to the external auditory canal it can be considered the sme because of the small sound velocity dispersion of in air.

This conversion takes place under the law of conservation and transformation of energy. The law, in the form $\frac{\mathrm{W}_{\mathrm{nf}}}{\mathrm{W}_{\mathrm{nc}}}=\frac{\mathrm{W}_{\mathrm{nf}}^{*}}{\mathrm{~W}_{\mathrm{nc}}^{*}}$, leads to the relation

$$
\frac{\mathrm{W}_{\mathrm{nf}}}{\mathrm{W}_{\mathrm{nc}}}=\frac{\mathrm{I}_{\mathrm{nf}}}{\mathrm{I}_{\mathrm{nc}}}=\frac{\Lambda_{\mathrm{f}}}{\Lambda_{\mathrm{c}}} \frac{\mathrm{v}_{\mathrm{c}}}{\mathrm{v}_{\mathrm{f}}}=\mathrm{G}(\mathrm{f}) .
$$

This means that a sense of sound at a frequency different from the standard requires great energy, which is caused by an significant increase distances between receptors $\Lambda_{\mathrm{f}}$ with varying frequency. Perhaps this is due to the greater volume of intra-labyrinth liquid above receptors, which must vibrate for a physiological sensation of sound.

The value $G(f)$ acquires a meaning of the psychophysical frequency equivalent for the sounds of equal loudness (Figure 1c). Note two it features. For the equivalent we note two comments. The first comment is states that the absolute increment of the relative level of intensity of sound with respect to the n-level for tones of equal loudness is the absolute increment of psychophysical equivalent: $\Delta\left(\frac{\mathrm{I}_{\mathrm{nf}}}{\mathrm{I}_{\mathrm{nc}}}\right)=\frac{\Delta \mathrm{I}_{\mathrm{nf}}}{\mathrm{I}_{\mathrm{nc}}}=\Delta \mathrm{G}(\mathrm{f})$, that leads to the relation $\Delta \mathrm{I}_{\mathrm{nf}}=\mathrm{I}_{\mathrm{nc}} \Delta \mathrm{G}(\mathrm{f})$. Last equality implies second comment - about the relative increment of the sound intensity in frequency by n-level, which is

$$
\left(\frac{\Delta \mathrm{I}}{\mathrm{I}}\right)_{\mathrm{n}}=\frac{\Delta \mathrm{I}_{\mathrm{nf}}}{\mathrm{I}_{\mathrm{nf}}}=\frac{\mathrm{I}_{\mathrm{nc}}}{\mathrm{I}_{\mathrm{nf}}} \Delta \mathrm{G}=\frac{\Delta \mathrm{G}}{\mathrm{G}} .
$$

Now back to the Weber law for the rationale of sound perception of arbitrary frequency and intensity.

According to Weber, the increment of perception of tones loudness $\Delta \mathrm{E}$ is proportional to the increment of the relative intensity of the sound $(\Delta \mathrm{I} / \mathrm{I})$, i.e. $\Delta \mathrm{E}=\mathrm{k}(\Delta \mathrm{I} / \mathrm{I})$. But increment of sound intensity $\Delta \mathrm{I}$ is reflected by variations as in energy (intensity level) $\Delta \mathrm{I}_{\mathrm{L}}$, and in frequency $\Delta \mathrm{I}_{\mathrm{f}}$, and generally represents the sum 


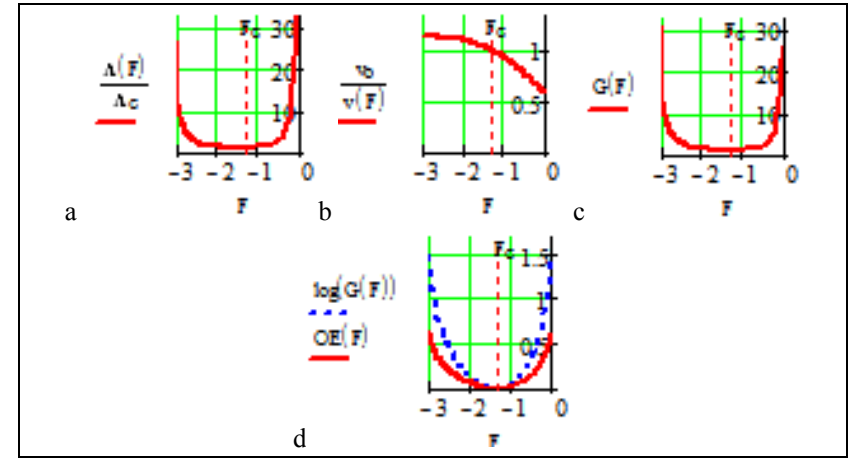

Figure 1. Modeling of equal loudness tones: calculation of relative distances between the receptors for the outer hair cells (a), of the relative sound velocity at different frequencies (b), the dimensionless quantity G(f) as the psychophysical frequency equivalent of tones equal loudness (c), of the logarithm of psychophysical frequency equivalent $G(f)$ as a frequency function $\mathrm{E}(\mathrm{f})$, (d) Graph of frequency function $\mathrm{E}(\mathrm{f})$, its representation as a normalized function in form $\log (G(f))$.

$$
\begin{aligned}
\Delta \mathrm{E}=\mathrm{k}_{\mathrm{L}}\left(\frac{\Delta \mathrm{I}}{\mathrm{I}}\right)_{\mathrm{f}_{\mathrm{c}}}+\mathrm{k}_{\mathrm{f}}\left(\frac{\Delta \mathrm{I}}{\mathrm{I}}\right)_{\mathrm{n}}=\mathrm{k}_{\mathrm{L}}\left(\frac{\Delta \mathrm{I}}{\mathrm{I}}\right)_{\mathrm{f}_{\mathrm{c}}}+\mathrm{k}_{\mathrm{f}} \\
\left(\frac{\Delta \mathrm{G}}{\mathrm{G}}\right)_{\mathrm{n}}
\end{aligned}
$$

with the corresponding coefficients of proportionality $\mathrm{k}_{\mathrm{L}}$ and $\mathrm{k}_{\mathrm{f}}$.

Turning to the infinitely small, we obtain the differential equation

$$
\mathrm{dE}=\mathrm{k}_{\mathrm{L}}\left(\frac{\mathrm{dI}}{\mathrm{I}}\right)_{\mathrm{f}_{\mathrm{c}}}+\mathrm{k}_{\mathrm{f}}\left(\frac{\mathrm{dG}}{\mathrm{G}}\right)_{\mathrm{n}},
$$

Integrating which for $\mathrm{E}$ from 0 to $\mathrm{E}$, for I from Ioc to $\mathrm{I}$, and for $\mathrm{G}$ from $\mathrm{G}_{\mathrm{nc}}=1$ to $\mathrm{G}$, we have

$$
\int_{0}^{\mathrm{E}} \mathrm{dE}=\mathrm{k}_{\mathrm{L}} \int_{\mathrm{I}_{\mathrm{oc}}}^{\mathrm{I}} \frac{\mathrm{dI}}{\mathrm{I}}+\mathrm{k}_{\mathrm{f}} \int_{1}^{\mathrm{G}} \frac{\mathrm{dG}}{\mathrm{G}}=\mathrm{k}_{\mathrm{L}} \ln \frac{\mathrm{I}}{\mathrm{I}_{\mathrm{oc}}}+\mathrm{k}_{\mathrm{f}} \ln \mathrm{G} .
$$

Transition to the decimal logarithms gives the general solution

$$
E=\frac{k_{L}}{\lg e} \log \frac{I}{I_{o c}}+\frac{k_{f}}{\lg e} \log G .
$$

The boundary condition with the standard frequency $\mathrm{f}=$ $f_{c}=1 \mathrm{kHz}$, at which $I_{n f}=I_{n c}$, gives $E_{n f}=E_{n c}$ (for tones of equal loudness) and $\log \left(\mathrm{I}_{\mathrm{nc}} / \mathrm{I}_{\mathrm{oc}}\right)=\mathrm{L}_{\mathrm{nc}}=\mathrm{E}_{\mathrm{nc}}$ (for declarative agreement), as well as $\mathrm{G}_{\mathrm{nc}}=1$ or $\log \mathrm{G}=0$, and leads to the fact that $k_{L} / \log (e)=1$. Finally

$$
\mathrm{E}=\log \frac{\mathrm{I}}{\mathrm{I}_{\mathrm{oc}}}
$$

We obtain the law of Weber - Fechner for hearing in the usual form for the standard frequency.

The boundary condition with frequency $\mathrm{f} \rightarrow \mathrm{f}_{\mathrm{o}}=20 \mathrm{~Hz}$ (and $/$ or $\mathrm{f} \rightarrow \mathrm{f}_{\mathrm{mo}}=20 \mathrm{kHz}$ ) at which $\mathrm{I}_{\mathrm{nf}}=\mathrm{I}_{\mathrm{mo}}=10 \mathrm{~W} / \mathrm{m}^{2}$,
$E_{n f}=E_{m o}$, and $E_{m o}=E_{n c}$ (for tones of equal loudness) and $\log \left(\mathrm{I}_{\mathrm{mo}} / \mathrm{I}_{\mathrm{oc}}\right)=\mathrm{L}_{\mathrm{mo}}=\mathrm{E}_{\mathrm{mo}}$ (for declarative agreement) and $\log \frac{I_{n c}}{I_{o c}} \log \left(I_{n c} / I_{o c}\right)=L_{n c}=L$, leads to the fact that $E_{n c}=$ $\lg \frac{I_{\mathrm{mo}}}{I_{\mathrm{oc}}}+\frac{\mathrm{k}_{\mathrm{f}}}{\lg \mathrm{e}} \lg \mathrm{G}_{\mathrm{mo}}=\mathrm{L}_{\mathrm{mo}}+\frac{\mathrm{k}_{\mathrm{f}}}{\lg \mathrm{e}} \lg \mathrm{G}_{\mathrm{mo}}, \frac{\mathrm{k}_{\mathrm{f}}}{\lg \mathrm{e}}=(\mathrm{L}-$ $\left.\mathrm{L}_{\mathrm{mo}}\right) \frac{1}{\lg \mathrm{G}_{\mathrm{mo}}}$, and $\mathrm{E}=\mathrm{L}+\left(\mathrm{L}_{\mathrm{nc}}-\mathrm{L}_{\mathrm{mo}}\right)$ or

$$
\begin{gathered}
E=\log \frac{I}{I_{\mathrm{oc}}}+\left(\log \frac{I}{I_{\mathrm{oc}}}-\log \frac{I_{\mathrm{mo}}}{I_{\mathrm{oc}}}\right) \frac{\log \mathrm{G}}{\log \mathrm{G}_{\mathrm{mo}}}= \\
=\log \frac{\mathrm{I}}{\mathrm{I}_{\mathrm{oc}}}+\log \frac{\mathrm{I}}{\mathrm{I}_{\mathrm{mo}}} \frac{\log \mathrm{G}}{\log \mathrm{G}_{\mathrm{mo}}} .
\end{gathered}
$$

We note two singularities the second term in equation solving. It consists of two multipliers. For $\log G$ on the standard frequency for any n-level of intencity $\log G_{n c}=0$, at the maximum and minimum frequencies of perceived $f_{m o}$ $=20 \mathrm{kHz}$ and $\mathrm{f}_{\mathrm{o}}=20 \mathrm{~Hz}$ have $\log \mathrm{G}_{\mathrm{mo}} \operatorname{loge} \rightarrow 1$, so that the function $\mathrm{E}(\mathrm{f})=\log \mathrm{G}(\mathrm{f}) \log \mathrm{e} \in[0 ; 1]$ can be regarded as a normalized (Fig. 1d). Let us call this function $\mathbb{E}$ (f) as frequency function, then

$$
\mathrm{E}=\mathrm{L}+\log \frac{\mathrm{I}}{\mathrm{I}_{\mathrm{mo}}} \mathrm{E} .
$$

The second multiplier $\log \frac{\mathrm{I}}{\mathrm{I}_{\mathrm{mo}}}=\log \left(\frac{\mathrm{I}}{\mathrm{I}_{\mathrm{oc}}} \cdot \frac{\mathrm{I}_{\mathrm{oc}}}{\mathrm{I}_{\mathrm{mo}}}\right)=\log \left(\frac{\mathrm{I}}{\mathrm{I}_{\mathrm{oc}}}\right) \log \left(\frac{\mathrm{I}_{\mathrm{mo}}}{\mathrm{I}_{\mathrm{oc}}}\right)=\mathrm{L}-\mathrm{L}_{\mathrm{mo}}$ - is the sound level relative to the upper comfort intensity $\mathrm{I}_{\mathrm{mo}}$. Let us call it as the converts (versus Level - vers-L) with the designation $\Gamma$. For $\mathrm{L}<\mathrm{L}_{\mathrm{mo}}$ (for comfortable sound intensities) converts level $\mathbb{\Gamma}<0$, and vice versa. In the brief description final result

$$
\mathrm{E}=\mathrm{L}+\mathbb{\Gamma} \mathrm{E}
$$

Means that loudness the tone E, perceived by hearing the sounds of arbitrary frequency f and the intensity level L, is equal to the sound intensity level $\mathrm{L}$, decreased $(\Gamma<0)$ by the product of the converts level of intensity and frequency of the sound function at this frequency. form.

Equation (9) is the Weber's law for hearing in author

\section{The auditory Weber law (by author) in 3-D as tones (sounds) loudness surface}

Function (9) can be represented geometrically surface, mathematical modeling which is shown in Figure 2 and 3. To identify let us called its as the loudness surface. Figure 2 explains the nature of tones equal loudness and reveals the mechanisms of perception of tones of various parameters caused by the sounds of different frequencies and intensities.

Partially transparent loudness surface is presented in a full color palette. 


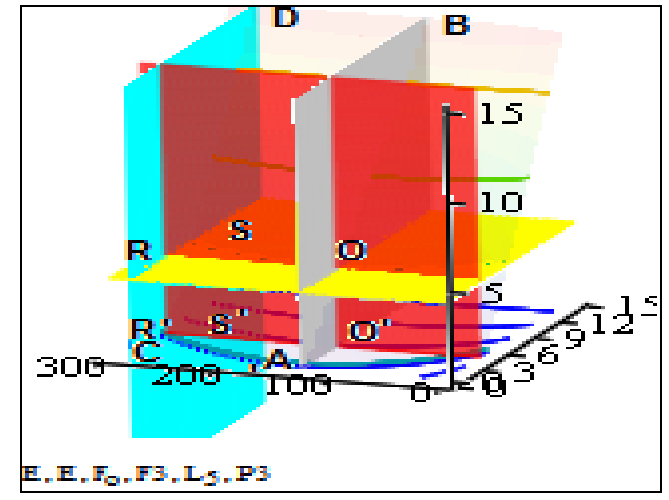

Figure 2. Graphical representation of the Weber's law for a hearing in the author's form and loudness surface in the 3-D coordinate system ELF: axis of the sound intensity levels $\mathrm{L}$, bel, directed to the right-up, the logarithmic axis of relative sound frequencies $\mathrm{F}=\log \left(\mathrm{f} / \mathrm{f}_{\mathrm{mo}}\right)$, directed to the left (scale of 100 units. $=-1$ ), the vertical axis of tones loudness, E, decaphon.

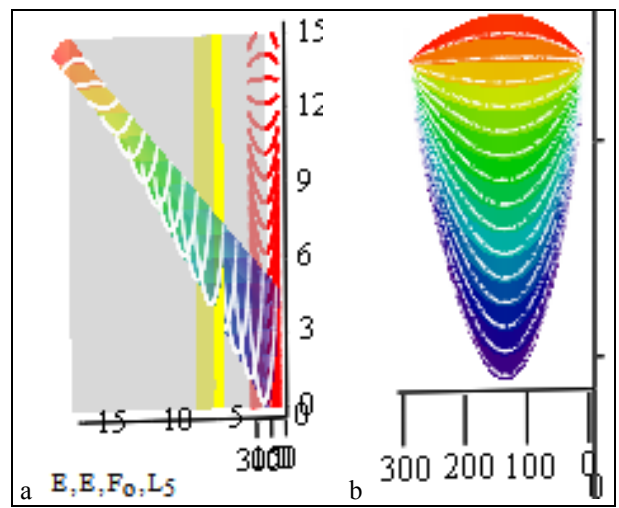

Figure 3. Surface loudness in 3D coordinate system ELP: a - as the distribution surface of the tones loudness level E (horizontal axis directed to the left, decaphon) in sound intensity levels L (vertical axis, bel) and the relative frequency of the sound $\mathrm{F}$ (horizontal axis directed to left) with clipping planes $\mathrm{L}=5 \mathrm{~B}$ (opaque yellow) and $\mathrm{F}$, corresponding to the standard frequency $f_{c}$ (translucent gray) and the card surface levels $E(L, F)$ on the basis of LF as isophons family, $\mathrm{b}$ - top view.

Gray vertical plane corresponds to the standard frequency $\mathrm{f}_{\mathrm{c}}=1 \mathrm{kHz}\left(\mathrm{F}_{\mathrm{c}}=-1.301\right)$, its section of the surface loudness, line $\mathrm{AB}$, describes the tones standard pitch in 1000 mel of an arbitrary loudness $\mathrm{E}$ (from 0 to 15 decaphon $=150$ phon), perceived by ear during stimulation of receptors by sounds of standard frequency $f_{c}$ and arbitrary intensity I (arbitrary intensity level L).

Blue vertical plane by the line CD describes the tones of arbitrary parameters. Translucent red vertical plane fixes the sound intensity level $\mathrm{L}=5 \mathrm{~B}=50 \mathrm{~dB}$. The section of the loudness surface by yellow opaque horizontal plane, line $\mathrm{OS}$, fixes the tones of equal loudness in level $\mathrm{E}=5$ decaphon $=50$ phon.
RS sets an increment interval of a sound intensity level $\Delta \mathrm{L}$, which is required to maintain the tones loudness at the specified level $\mathrm{E}$, while the intensity increment level $\Delta \mathrm{L}$ with frequency proportional to the increment of function $\Delta \mathrm{G}$, corresponds OR.

Projection of the loudness surface on the coordinate plane describes the picture in a planar version. More visual picture is observed when turning the coordinate axes (Fig. 3a). If on the loudness surface viewed from above, is possible to observe unthinkable planar picture similar to Fig. $3 \mathrm{~b}$ : Isophons provided on it are located in parallel planes and cannot overlap.

\section{INSTEAD OF DISCUSSING AND CONCLUSIONS}

In conclusion, we note that the presented substantiation is not unique. For mathematical modeling and calculation of the tones loudness $\mathrm{E}(\mathrm{I}, \mathrm{f})$ in computational biology convenient to use the (9) in the form $E(L, f)=L-\left(L_{m o}-L\right)$ $\mathrm{E}(\mathrm{f})$ or an invariant, assuming that $\mathrm{E}=\mathrm{L}=\mathrm{E}(\mathrm{L}, \mathrm{f})$ - the required loudness.

When this $E(L, f)-E(L, f) \cdot\left(E(f)=L-L_{\text {mo }} E(f)\right.$, whence $\mathrm{E}(\mathrm{I}, \mathrm{f})$ as a function of the sound intensity and frequency

$$
E(I, f)=\frac{\log \frac{I}{I_{o c}}-L_{m o} O E(f)}{1-O E(f)}
$$

or as a function of sound pressure level and the sound frequency

$$
\mathrm{E}(\Delta \mathrm{p}, \mathrm{f})=2 \frac{\log \frac{\Delta \mathrm{p}}{\Delta \mathrm{p}_{\mathrm{oc}}}-\mathrm{L}_{\text {mo }} \mathrm{OE}(\mathrm{f})}{1-\mathrm{OE}(\mathrm{f})}
$$

Psychophysical evaluation by hearing sense of sound's stimulus is to determine the limits of the tones loudness levels at which a sound effect would be observed without a hearing dysfunction and destructions of inner ear structures. Weber's law in the author form is the biophysical basis for the development of psycho-physical mechanisms of morphological and physiological (functional) nature of these effects.

\section{REFERENCES}

[1] Weber E.H. De Pulsu, Resorptione, Auditu et Tactu. // Annotationes Anatomicae et Physiologicae. Lipsiae: CF Kohler, 1834.

[2] Fechner G. Th. Elemente der Psychophysik. // Leipzig, Breitkopf and Hartel, 1858.

[3] Patent № 2146878 RU, C1, 27.03.2000.

[4] Patent № 2184485 RU, C2, 10.06.2002.

[5] Ovchinnikov EL. Ivanov VV, Ovchinnikova YuV. Acoustic-wave hearing model, initial stage: the sound transduction in the inner ear. // European Science and Technology: $3^{\text {nd }}$ International scientific conference, Munich, Germany, 2012, p. 524-535. 